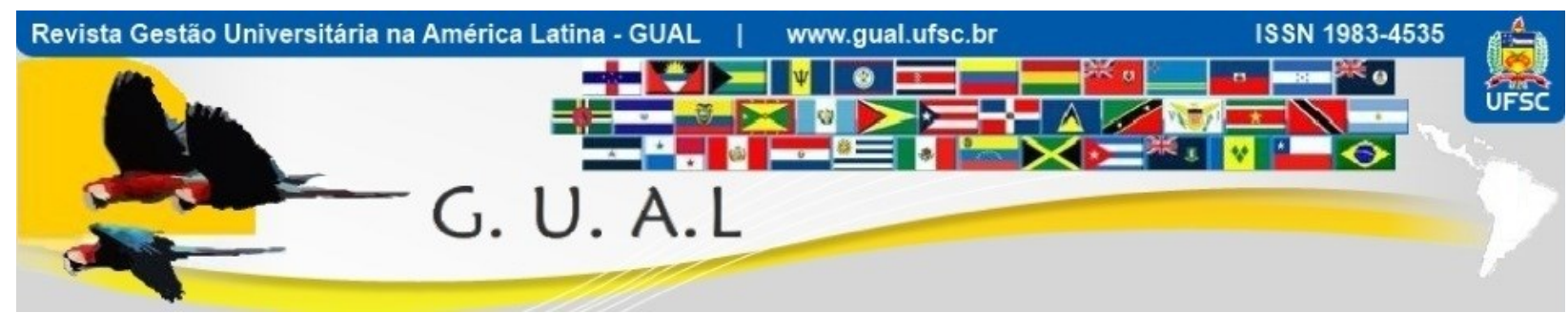

DOI: http://dx.doi.org/10.5007/1983-4535.2020v13n1p48

\title{
FATORES DETERMINANTES DA EVASÃO NOS CURSOS DE CIÊNCIAS CONTÁBEIS NO BRASIL
}

\section{DETERMINANT FACTORS OF DROPOUT IN ACCOUNTING PROGRAMS IN BRAZIL}

\section{Izaqueline Jhusmicele Alcântara da Silva, Graduanda https://orcid.org/0000-0002-2490-6304 izaqueline@hotmail.com}

Universidade Federal de Uberlândia | Faculdade de Ciências Contábeis Uberlândia | Minas Gerais | Brasil

Vitor Hideo Nasu, Mestre https://orcid.org/0000-0002-5176-6634 vnasu@usp.br Universidade de São Paulo | Faculdade de Economia, Administração e Contabilidade São Paulo | São Paulo | Brasil

Edvalda Araujo Leal, Doutora https://orcid.org/0000-0002-7497-5949 edvalda@ufu.br

Universidade Federal de Uberlândia | Faculdade de Ciências Contábeis Uberlândia | Minas Gerais | Brasil

Gilberto José Miranda, Doutor http://orcid.org/0000-0002-1543-611X gilbertojm@ufu.br

Universidade Federal de Uberlândia | Faculdade de Ciências Contábeis Uberlândia | Minas Gerais | Brasil

Recebido em 19/novembro/2018

Aprovado em 15/outubro/2019

Publicado em 02/janeiro/2020

Sistema de Avaliação: Double Blind Review

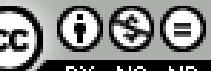

Esta obra está sob uma Licença Creative Commons Atribuição-Uso. 


\title{
RESUMO
}

A evasão é um fenômeno em crescimento que aflige as Instituições de Ensino Superior (IES) públicas e privadas. As medidas de conter a evasão dependem de ações e programas de assistência e de orientação a serem implementados pelas próprias IES. Assim, torna-se relevante conhecer os atributos de alunos e instituições associados ao fenômeno da evasão, em particular no curso de Ciências Contábeis no Brasil. Desta forma, esta pesquisa buscou mapear as características da IES, do curso e dos alunos que determinam a evasão. Para isso, foram levantados os dados públicos do Censo Nacional da Educação Superior de 2015 e 2016. A seleção das variáveis ocorreu a partir do levantamento de estudos anteriores relacionados à evasão. Para o cálculo da evasão anual, utilizou-se a metodologia empregada por Silva Filho et al. (2007). Para o tratamento dos dados, foi realizada a análise descritiva e a regressão logística binomial. Evidenciou-se que a taxa média de evasão geral é alta, indicando que $31 \%$ dos alunos dos cursos de Ciências Contábeis no Brasil evadem. Os achados contribuem para que gestores e coordenadores dos cursos implementem ações e estratégias para aumentar a eficiência dos serviços educacionais por meio da redução da evasão.

Palavras-chave: Taxas de Evasão. Fatores da Evasão. Ensino Superior. Ciências Contábeis. Ações e Programas.

\begin{abstract}
Dropout is a growing phenomenon afflicting public and private higher education institutions (HEIs). The measures to contain dropout depend on actions and programs of assistance and guidance to be implemented by the HEIs themselves. Thus, it becomes relevant to know the attributes of students and institutions associated with the dropout phenomenon, in particular in the Accounting Sciences Courses in Brazil. Therefore, this research sought to map the HEI characteristics, the program and the students that determine the dropout. For this end, public data from the National Higher Education Census of 2015 and 2016 were collected. The variables selection occurred from the previous dropout literature. To calculate the annual student dropout, the Silva Filho et al.'s (2007) methodology was used. For data analysis, descriptive statistics and binomial logistic regression were performed. It was evidenced that the average rate of general dropout is relatively high, indicating that $31 \%$ of students enrolled in Accounting Sciences Courses in Brazil dropped out. The findings contribute to the programs managers and coordinators to implement actions and strategies to increase the efficiency of educational services through the dropout reduction.
\end{abstract}

Keywords: Dropout Rate. Dropout Factors. Higher Education. Accounting. Actions and Programs. 


\section{INTRODUÇÃO}

A evasão é um fenômeno em crescimento que aflige as Instituições de Ensino Superior (IES) públicas e privadas. No Brasil, os estudos sobre a evasão universitária são recentes, tendo sido iniciados em meados do Século XX, no momento marcado pelo crescimento do ensino privado e da rede federal pública, notadamente, pela introdução de novos métodos de seleção (GILIOLI, 2016).

Segundo o relatório do Sindicato das Mantenedoras de Ensino Superior (SEMESP, 2016), de 2000 a 2014, o número de IES manteve-se em ascensão, totalizando 2.368 instituições em 2014, com crescimento de 106\% no setor privado e de $69 \%$ no setor público. Dentre os mais procurados nas IES privadas, o Curso de Ciências Contábeis posicionou-se em quarto lugar entre os cursos presenciais e em quinto entre os cursos de Educação a Distância (EaD), conforme o número de matrículas registrados (INEP, 2016).

Da mesma forma, a evasão total cresceu nos últimos anos, apresentando uma taxa de 25,4\% nos cursos presenciais e de 32\% nos cursos EaD (SEMESP, 2016). Conforme aponta o estudo de Gois (2016), os prejuízos sociais e públicos com a evasão de jovens somam a quantia de 50 bilhões de reais anuais. Tinto (1975), a seu turno, indica que as causas de evasão estão relacionadas a fatores externos e internos à instituição, ou seja, dizem respeito ao período pré-universitário (Atributos pré-ingresso e Metas e Compromisso) e ao período universitário (Experiências institucionais, Integração e Metas e compromissos).

Gilioli (2016) explana que as medidas de antievasão dependem de ações e programas de assistência e de orientação a serem implementados, desenvolvidos ou aperfeiçoados pelas próprias instituições de ensino superior. Assim, é preciso que se conheçam os atributos de alunos e instituições associados ao fenômeno. Nesse sentido, surge a questão motivadora deste estudo: Quais características das instituições e dos alunos de Ciências Contábeis estão relacionadas às taxas de evasão nas IES brasileiras?

Dessa forma, o propósito deste estudo é mapear as características das IES, dos cursos e dos alunos e relacioná-las aos índices de evasão das instituições. Para isso, utilizando os dados públicos do Censo Nacional da Educação Superior, fez a seleção das variáveis com base na literatura abordada e, posteriormente, qualificou-se a uma das categorias do Modelo de Integração do Estudante de Tinto (1975). Conjuntamente, calculou-se as taxas de evasão dos cursos de Ciências Contábeis conforme a metodologia adotada por Silva et al. (2007). 
A pesquisa torna-se relevante ao apresentar um panorama de evasão no ensino superior nos Cursos de Ciências Contábeis e levantar junto à literatura as causas de evasão mais frequentes nos cursos de ensino superior. Mediante os resultados apurados, são propostas ações e estratégias para o combate à evasão no curso de Ciências Contábeis. Os achados contribuem para que gestores e coordenadores do curso de ciências contábeis implementem ações e estratégias para permanecia do aluno e, consequentemente, a redução do índice de evasão.

\section{REFERENCIAL TEÓRICO}

\subsection{PESQUISAS INICIAIS SOBRE EVASÃO}

Os estudos sobre a evasão no ensino superior brasileiro foram direcionados, inicialmente, para o levantamento estatístico e também por meio de estudos de casos relacionados à análise dos fatores e das causas da ocorrência desse fenômeno em universidades, cursos, áreas de conhecimento ou regiões específicas (ADACHI, 2009). Entretanto, tais pesquisas não se voltavam para a compreensão do problema de forma que impulsionassem intervenções que auxiliassem a reduzir as taxas de retenção e evasão (ADACHI, 2009).

Moehlecke (2007) pontua que estudos sobre a evasão estavam centrados na educação básica e que havia uma escassez de pesquisas no âmbito do ensino superior. Essas pesquisas, em sua maioria, restringiam-se à descrição do processo sem, no entanto, analisar as causas e/ou a propor modelos teóricos que procurassem explicar o fenômeno, como demonstra o estudo sobre a retenção e o abandono estudantil na América Latina e Caribe realizado por Munizaga, Cifuentes e Beltrán (2018). Segundo os autores, 51\% dos 81 artigos analisados eram voltados para a caracterização do fenômeno, enquanto apenas $5 \%$ e $6 \%$ propuseram, respectivamente, ações de intervenção e avaliação da intervenção.

Frente a esse cenário, criou-se, em 1996, por incentivo da Secretaria de Educação Superior do Ministério da Educação e do Desporto (SESU), vinculada ao Ministério da Educação-MEC, a Comissão Especial para o Estudo da Evasão devido à necessidade de se instituir uma metodologia comum e uma fórmula para o cálculo do índice a fim alcançar a confiabilidade dos dados (ADACHI, 2009). Além disso, um dos primeiros objetivos da Comissão Especial foi o de analisar o conceito de evasão, o qual foi definido como "a saída definitiva do aluno de seu curso de origem, sem concluí-lo” (MEC, p. 15, 1996). 
Da saída ao reingresso do aluno em outro curso ou IES, devem-se considerar os impactos nos índices de evasão conforme a sua forma de ingresso (transferências de outras IES, transferências ex-officio, mudança de curso na mesma IES, matrícula cortesia, programas de estudantes, convênios, acordos internacionais e diplomados, reingresso, dentre outros.) (SILVA FILHO; LOBO, 2012).

Lobo (2012, p. 8) explana que, mesmo que o aluno que mudou de curso ou de IES tenha a sua vaga preenchida por outro aluno, sua saída causa perda para o curso e deve ser tratada como evasão, podendo-se chegar à conclusão de que a evasão de curso é "aquela em que o aluno deixa um curso por qualquer razão". Para o autor, a evasão vai além de confrontar as entradas e as saídas, sendo necessário identificar as razões que envolvem a permanência e a saída dos alunos a fim de promover ações para evitar que ocorram outras perdas pelos mesmos motivos (LOBO, 2012).

O MEC (1996) define e reconhece três tipos de evasão: (i) evasão de curso, que se dá quando o estudante se desliga do curso superior em situações diversas, tais como: abandono (deixa de se matricular), desistência (oficial), transferência ou reopção (mudança de curso), exclusão por norma institucional; (ii) evasão da instituição, a qual ocorre quando o estudante se desliga da instituição na qual está matriculado; (iii) evasão do sistema, que ocorre quando o estudante abandona, de forma definitiva ou temporária, o ensino superior. Para Moehlecke (2007), cada tipo de evasão é resultado de diferentes fatores que exigiriam respostas específicas.

Silva Filho et al. (2007) abordam a evasão sob duas concepções: evasão anual média, que se refere ao percentual de alunos matriculados que, não tendo obtido aprovação, não se matricularam no ano/semestre seguinte; e a evasão total, em que se observa a quantidade de alunos ingressantes em um determinado período de tempo que não obtiveram a diplomação/titulação.

Quanto aos fatores que levam à evasão do estudante, a Comissão Especial sobre Evasão (MEC, 1996) assim os distingue: fatores que se relacionam ao próprio estudante; fatores relacionados ao curso e à instituição; e fatores socioculturais e econômicos externos (MEC, 1996). Spady (1970), um dos pesquisadores pioneiros sobre o tema, com base na teoria social de Durkheim, comparou o abandono escolar a um ato de suicídio. Segundo sua teoria, há dois componentes sociais principais inerentes ao processo de evasão: o primeiro está relacionado ao sucesso acadêmico que ocorre quando os objetivos, interesses e personalidade interagem com o sistema acadêmico, fenômeno denominado de "congruência 
normativa”. Já o segundo se refere às relações estabelecidas, as quais constroem uma rede de "suporte em amizade".

Posteriormente, Tinto (1975), com base nos estudos de Spady (1970; 1971), aponta que o suicídio acadêmico decorre do nível de integração do indivíduo, da falta de integração à vida universitária. Segundo o autor, quando não ocorre a integração total às atividades extracurriculares e aos negócios sociais aumenta a probabilidade de o aluno evadir-. Para analisar esse processo de evasão, Tinto (1975) desenvolve o Modelo de Integração do Estudante (MIE), o qual analisa as variáveis de forma longitudinal. Por se tratar da base desta pesquisa, a teoria e o modelo de Tinto (1975) serão tratados a seguir.

\subsection{O PROCESSO DE EVASÃO À LUZ DA TEORIA DE INTEGRAÇÃO DO ESTUDANTE - TINTO}

Para Tinto (1975), o processo de evasão decorre do nível de integração social e acadêmica do estudante à instituição de ensino. Essa integração ao ambiente acadêmico está relacionada aos atributos individuais (raça, sexo, habilidades acadêmicas), às experiências anteriores (formação e histórico escolar, desenvoltura nos relacionamentos sociais) e ao contexto familiar (status socioeconômico, ambiente familiar, valores e expectativas).

No Modelo de Integração do Estudante (MEI), desenvolvido por Tinto em 1975, as causas são analisadas em dois períodos: no período pré-universitário, as causas estão relacionadas à fatores internos à instituição e, no período universitário, decorrem de fatores externos. As causas internas são aquelas relacionadas à instituição quanto ao sistema acadêmico e social; já as externas estão relacionadas às características do estudante e aos fatores externos (TINTO, 1993 apud SANTOS, 2013). A Figura 1 apresenta a última revisão do Modelo desenvolvido por Tinto (1975).

Tinto (1975) analisa, longitudinalmente, as variáveis de três grandes grupos (sistema institucional, sistema acadêmico e comunidade externa). A esses grupos estão relacionadas as características do estudante, suas intenções/objetivos e compromisso, as expectativas com a carreira, as características do curso e o nível de integração acadêmico e social. Posteriormente, ao revisar seu modelo, Tinto (1993 apud SANTOS, 2013) acrescenta as seguintes variáveis: aprendizagem, finanças, ajustamento, incongruências, isolamento, dificuldade e compromissos externos. 
Figura 1 Modelo longitudinal do abandono institucional de Tinto (1993)

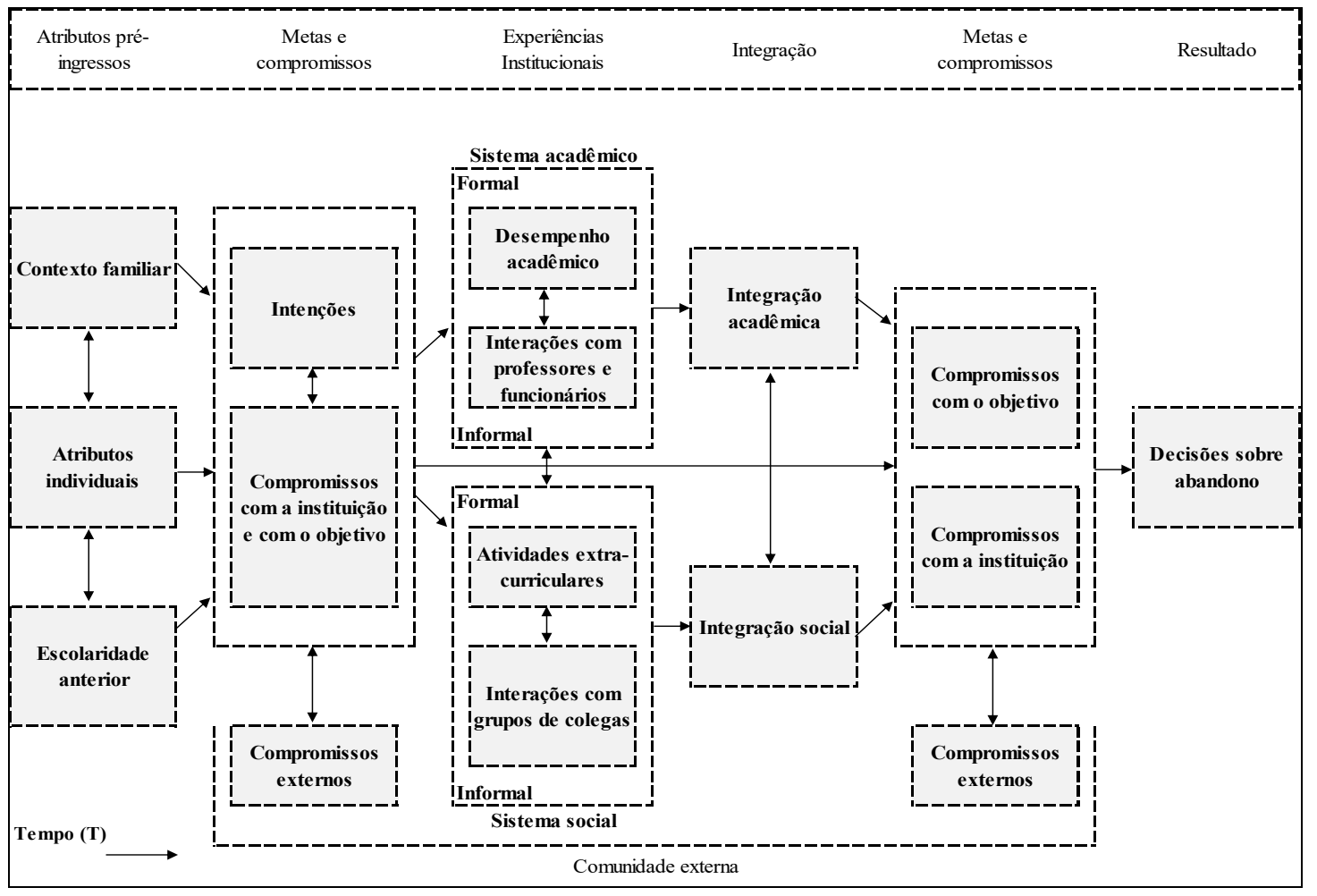

Fonte: Tinto (1993 apud SANTOS, 2013).

\subsubsection{Atributos Pré-Ingresso}

De acordo com Tinto (1975), os fatores pré-ingresso são decorrentes das causas externas à instituição. Caracterizadas no período pré-universitário, as mesmas subdividem-se em: contexto familiar, atributos individuais e escolaridade anterior.

No contexto familiar, destacam-se os fatores socioeconômicos, os quais se demonstram relevantes aos se relacionarem com as taxas atribuídas à evasão e à reprovação (DIOGO et al., 2016). Vasconcelos, Silva e Miranda (2013) identificaram, em um estudo com alunos evadidos do curso Ciências Contábeis e Atuarias, que 91\% deles trabalhavam no decorrer do curso para buscar a independência financeira e para ajudar os pais no sustento da família. Já 20\% alegaram que o motivo de evasão é a dificuldade em conciliar trabalho e estudo.

O estudo de Krüger Júnior et al. (2011) reforça as dificuldades de se conciliar trabalho e estudo, visto que os principais motivos de evasão se referiam à carga horária de trabalho excessiva (50\%) e à incompatibilidade de horário entre o trabalho e a universidade $(30 \%)$. Por sua vez, Furtado e Alves (2012), ao relacionar evasão e renda, constataram, na amostra de alunos evadidos, uma relação inversamente proporcional, ou seja, à medida que a renda 
aumentava, menores eram os índices de evasão, com exceção quando se tratava da última faixa de renda (mais de vinte salários mínimos).

No tocante aos atributos individuais, destaca-se o fato de a escolha do curso ocorrer precocemente, notadamente, por volta dos 15 anos, e, muitas vezes, sem o acompanhamento de um especialista em orientação vocacional (BUENO, 1993). Cunha, Nascimento e Durso (2014) expressam a importância de ações voltadas para a orientação. Em um estudo com alunos do curso de Ciências Contábeis, os autores identificaram que 91\% dos entrevistados relataram não ter tido nenhuma ajuda quanto à escolha profissional e, para $43 \%$ deles, o curso no qual se matricularam era a sua segunda opção.

Para Diogo et al. (2016), as tendências do mercado influenciam a permanência no curso. Complementa Bueno (1993) que os estudantes de áreas com baixo prestígio social evadem-se mais facilmente diante da primeira dificuldade quando comparados a alunos de cursos que garantem maior prestígio social, com boas condições de trabalho e sucesso financeiro. Nesse sentido, para Vasconcelos, Silva e Miranda (2013), a orientação vocacional deve ser trabalhada no Ensino médio por meio de palestras informativas, conversas com profissionais, pesquisas etc. Para os que já ingressaram no ensino superior, podem ser realizadas apresentações sobre a estrutura do curso (DIOGO et al., 2016).

Ainda, os estudos de Dias, Theóphilo e Lopes (2010), Krüger Júnior et al. (2011), Furtado e Alves (2012), Vasconcelos, Silva e Miranda (2013) e Vieira e Miranda (2015) constataram maiores taxas de evasão associadas aos alunos do gênero masculino. As diferenças entre gêneros foram constatadas estatisticamente pela pesquisa de Nagai (2015). Para o autor, as diferenças de percepção estão relacionadas à subjetividade, prioridades e experiências de cada pessoa.

No que se refere à escolaridade anterior, de acordo com a Comissão Especial (MEC, 1996), devido à precarização no sistema escolar, os estudantes ingressam no ensino superior com uma formação deficiente, o que potencializa as dificuldades de aprendizado, podendo levá-los a reprovações sucessivas. Diogo et al. (2016) complementam que as disparidades entre o Ensino Médio e o Ensino Superior contribuem para o aumento das taxas de evasão nos períodos iniciais, pois, por não estarem cientes dessas diferenças, os ingressantes podem ser levados ao sentimento de despreparo e inaptidão, resultando na sua evasão.

A pesquisa realizada por Furtado e Alves (2012) indica uma relação positiva entre a quantidade de disciplinas canceladas e a probabilidade de o estudante se evadir. Diogo et al. (2016) apontam a necessidade de as universidades auxiliarem os calouros para a adaptação a 
esse novo contexto. Entre as ações propostas pela Comissão Especial (MEC, 1996) para combater as dificuldades iniciais está o oferecimento de atividades de apoio pedagógico a estudantes com dificuldades de desempenho e a realização de ações pedagógicas organizadas em disciplinas com altas taxas de reprovação.

\subsubsection{Metas e Compromissos}

Ao iniciar a vida universitária, o estudante carrega consigo as características anteriores ao ingresso e essas passam a refletir na sua integração ao novo ambiente. Desse processo, surgem os compromissos com a meta de graduação e com a instituição. O primeiro tem por objetivo conseguir o diploma é inerente às características do aluno, como motivação e habilidade acadêmica, o que afeta diretamente a sua experiência universitária (TINTO, 1975). Já o compromisso institucional refere-se à expectativa pessoal de frequentar uma instituição de ensino superior e seu estabelecimento depende das características acadêmicas e sociais da universidade.

Em outra perspectiva, Furtado e Alves (2012) constataram que alunos casados ou divorciados têm maior probabilidade de evasão visto que os compromissos externos podem ter um peso maior. Nagai (2015) também encontrou diferenças estatísticas significativas quanto aos tipos de estado civil. No estudo de Dias, Theóphilo e Lopes (2010), 3,8\% dos 38 entrevistados alegaram como causa de evasão motivos pessoais que envolviam problemas de saúde e casamento.

\subsubsection{Experiências Institucionais}

As experiências institucionais influenciam o nível de integração do estudante ao sistema, envolvendo os aspectos formais e informais da vida universitária: desempenho acadêmico, participação em atividades extracurriculares, interação entre professores e funcionários e interação com os colegas de classe.

As pesquisas têm mostrado que o número de evadidos no primeiro ano tem sido consideravelmente superior aos demais (VIEIRA; MIRANDA, 2015). Os autores apontam que, nesse período, as causas estão relacionadas à inadaptação à vida universitária e/ou à área profissional. Nos anos subsequentes, as causas que levaram os alunos a se evadirem estavam relacionadas à insuficiência de aproveitamento acadêmico (VIEIRA; MIRANDA, 2015).

O sistema acadêmico está relacionado à infraestrutura física e humana da instituição (TINTO, 1993). Segundo o MEC (1996), as deficiências na infraestrutura contribuem para o 
aumento das taxas de evasão. Nesse sentido, a pesquisa de Krüger Júnior et al. (2011) constatou que $20 \%$ dos evadidos relacionaram a decisão de evasão ao fato de a infraestrutura da instituição não corresponder às suas expectativas. Segundo os autores, os ingressantes esperavam do ambiente uma infraestrutura mais atual, com acesso à internet, além de laboratórios de informática que permitissem o acesso a ferramentas de gestão e softwares que simulassem a prática.

Por sua vez, Diogo et al. (2016) apontam problemas referentes à natureza pedagógica. De acordo com as pesquisas de Krüger Júnior et al. (2011) e Vasconcelos, Silva e Miranda (2013), um percentual relativo de alunos evade por não se adaptar às metodologias adotadas pelos professores, à falta de didática, por não conseguir uma boa relação professor-aluno e, principalmente, pela falta de aproximação da teoria com prática. Para Bueno (1993) e Diogo et al. (2016), as instituições devem valorizar a função docentes e incentivá-los a participar de programas de formação continuada.

A instituição, ao promover eventos de confraternização entre professores e alunos, recepção aos ingressantes, oferecer programas de pesquisa e extensão, visitas técnicas, empresa júnior etc., estará propiciando a integração do discente ao sistema social, contribuindo, assim, para sua permanência no curso (TINTO, 1993; KRÜGER JÚNIOR et al., 2011).

Conforme estudo de Nagai (2015), os alunos apontaram como outros fatores causadores da evasão: pressão psicológica por parte de professores; despreparo de outros alunos; falta de linhas de pesquisa, projetos de extensão e iniciação científica; falta de professores; didática adotada em sala de aula; falta de interação entre professor-aluno; e falta de motivação por parte dos professores.

\subsubsection{Integração Acadêmica e Social}

A integração social e acadêmica é resultado das experiências institucionais vividas pelo estudante. A primeira parte do desempenho acadêmico e do desenvolvimento intelectual do aluno refere-se a identificação do estudante às normas do sistema acadêmico. Nessa etapa, a integração do aluno irá refletir nas suas notas e na observância das regras da instituição. Já a integração social é resultado das interações positivas com grupos de estudantes e com os professores/servidores, além da participação em atividades extracurriculares (TINTO, 1975). Tinto (1975) explana a importância de manter o equilíbrio do aluno para a integração aos sistemas. 
Silva et al. (2017) identificaram que ações adotadas em maior grau pelas IES para combater a evasão estão direcionadas: à orientação profissional; à adaptação do estudante à vida universitária, à integração do discente à instituição e à comunidade; e à sua condição financeira, estando tais ações relacionadas às variáveis determinantes que influenciam a vida acadêmica do discente (TINTO, 1975, 1993; BUENTO, 1993; SILVA FILHO et al., 2007; DIAS; THEÓPHIO; LOPES, 2010).

Nesse sentido, verifica-se a relevância de se investigarem as características da instituição e dos alunos e suas influências na evasão. No próximo tópico, apresentam-se os procedimentos metodológicos adotados na pesquisa.

\section{PROCEDIMENTOS METODOLÓGICOS}

Esta pesquisa classifica-se como descritiva com abordagem quantitativa, pois atenta-se a observar, registrar e interpretar o fenômeno com a utilização de instrumentos estatísticos para análise dos dados sem a interferência do pesquisador.

Para este estudo, foram utilizados os microdados do Censo Nacional da Educação Superior dos anos de 2015 e 2016 disponibilizados no sítio eletrônico do Instituto Nacional de Estudos e Pesquisas Educacionais Anísio Teixeira (INEP). Os dados do Censo constituem-se no menor nível de desagregação e as informações referentes à educação superior são apresentados por Aluno, por Docente, por Curso e por Instituição. O período escolhido para a análise decorre do intuito de se encontrarem as taxas mais atuais de evasão (variável dependente) das IES brasileiras públicas e privadas de ensino presencial e a distância que ofertam o curso de Ciências Contábeis. E, por necessidade da metodologia de cálculo, foram utilizados os dados dos dois últimos Censos.

Para o cálculo da evasão anual, utilizou-se a metodologia empregada por Silva Filho et al. (2007), os quais, por sua vez, utilizaram os dados disponibilizados pelo INEP e cuja expressão é a seguinte:

$$
[E(n)=1-(M(n)-I(n)] /[M(n-1)-C(n-1))]
$$

Essa expressão compara a quantidade de alunos matriculados no ano anterior $\mathrm{M}(\mathrm{n}-1)$ que, não tendo obtido aprovação no curso $C(n-1)$, realizaram a sua matrícula no ano seguinte $[M(n)-I(n)]$, ou seja, trata-se do total de matriculados no ano seguinte $M(n)$ deduzido do total de ingressantes I(n). O resultado dessa equação representa aqueles que mantiveram o seu vínculo com a instituição/curso. A diferença entre 1, portanto, refere-se à perda de alunos de 
um ano para o outro (SILVA FILHO et al., 2007). Para Silva Filho e Lobo (2012), essa metodologia apresenta um cálculo mais exato do que outras metodologias internacionais e, portanto, fornece uma descrição mais correta da realidade, por isso é utilizada nos estudos do Instituto Lobo com dados agregados para encontrar as taxas anuais de evasão.

Conforme relatado por Silva Filho e Lobo (2012), no Censo de 2009, e ainda observado os anos de 2015 e 2016, nos dados por ingresso não são apresentados aqueles relativos às outras formas de entrada. Assim, trabalhou-se nesta pesquisa com o número total de ingressantes (ingressos por processo seletivo e por outras formas) para calcular a evasão anual média do curso.

A seleção das variáveis independentes no banco de Dados do INEP deu-se a partir do levantamento de estudos anteriores relacionados à evasão e, posteriormente, alinhadas à Teoria de Integração do Estudante desenvolvida por Tinto (1975). Após a escolha das variáveis, os dados por Aluno, por Curso e por Instituição foram filtrados dos microdados do Censo Nacional da Educação Superior, permanecendo apenas aqueles referentes ao Curso de Ciências Contábeis. Devido a limitações próprias do banco de dados, não foi possível vincular as variáveis relacionadas aos Docentes ao curso de Ciências Contábeis e, portanto, não foram exploradas neste trabalho. Dessa forma, as variáveis usadas nas análises propostas para este estudo estão reportadas na Tabela 1.

Tabela 1 Variáveis do estudo

\begin{tabular}{lll}
\hline Sigla & Descrição & Mensuração \\
\hline EVAGER & Taxa de evasão da IES & Metodologia de Silva Filho et al. (2007) \\
CATADM & Categoria administrativa da IES (Pública, Privada, & Dummies para cada categoria \\
& Especial) & $1=$ Universidade; 0 = Outros \\
ORGACA & Organização acadêmica & $1=$ A distância; 0 = Presencial \\
MODENS & Modalidade de ensino & $1=$ Sim; 0 = Não \\
CURGRA & O curso é gratuito? & Dummies para cada categoria \\
TURALU & Turno que o aluno cursa a graduação (A distância, & $1=$ Branco; 0 = Não branco \\
ETNALU & Eatutino, Vespertino, Noturno, Integral) & $1=$ Feminino; 0 = Masculino \\
SEXALU & Sexo do aluno (Branco, Não branco, Não declarado) & Idade do aluno, em anos \\
IDAALU & Idade do aluno & $1=$ Sim; 0 = Não \\
FINEST & O aluno possui financiamento estudantil? & $1=$ Sim; 0 = Não \\
APOSOC & O aluno recebe apoio social da IES? & $1=$ Pública; 0 = Privada \\
ENSMED & $\begin{array}{l}\text { Tipo de escola que o aluno cursou o ensino médio } \\
\text { (Pública, Privada, Sem informação) }\end{array}$ & Percentual de horas integralizadas \\
\hline
\end{tabular}

Fonte: Dados da pesquisa. 
Consistente com o objetivo da pesquisa de se identificar os fatores relacionados às taxas de evasão das IES, foram consideradas as variáveis relacionadas à IES (CATADM, ORGACA), ao Curso (MODENS, CURGRA) e ao Aluno (TURALU, ETNALU, SEXALU, IDAALU, FINEST, APOSOC, ENSMED e TCHINT).

\section{ANÁLISE E DISCUSSÃO DOS RESULTADOS}

Inicialmente, apresentam-se as estatísticas descritivas das variáveis do estudo na Tabela 2. Para as variáveis quantitativas, reportam-se as médias e os desvios-padrão. Para as variáveis qualitativas, evidenciam-se as frequências absolutas e relativas.

A taxa média de evasão geral é relativamente alta, indicando que $31 \%$ dos alunos dos cursos de Ciências Contábeis no Brasil evadem. Relativamente às variáveis da IES, destaca-se que a maioria dos alunos estudam em IES privadas (89\%), sendo a organização acadêmica predominante a universidade (51\%). Em relação às variáveis do 'Curso', nota-se que a maioria dos alunos estuda por meio da modalidade presencial $(69 \%)$ e que necessita pagar pelos seus estudos (90\%). As variáveis dos 'Alunos' indicam que a maior parcela estuda no período noturno (62\%), identifica-se como branca (34\%), é do sexo feminino (57\%), não possui financiamento estudantil para custear o curso (65\%), não possui apoio social da IES (86\%), cursou o ensino médio em instituição pública (75\%) e que já integralizou, em média, $43 \%$ da carga horária do curso de Ciências Contábeis.

Tabela 2 Estatísticas descritivas das variáveis do estudo

\begin{tabular}{lcccc}
\hline Variáveis da IES & Tipo & $\mathbf{N}$ & Média/Freq. Absoluta & DP/Freq. Relativa \\
\hline$E V A G E R$ & Quantitativa & 512.971 & 0,31 & 0,22 \\
CATADM & Qualitativa & 514.886 & 514.886 & $100 \%$ \\
Pública & & & 52.769 & $10 \%$ \\
Privada & & 457.640 & $89 \%$ \\
Especial & & 4.477 & $1 \%$ \\
ORGACA & Qualitativa & 514.886 & 514.886 & $100 \%$ \\
Universidade & & & 260.940 & $51 \%$ \\
Outros & & & 253.946 & $49 \%$ \\
\hline Variáveis do Curso & Tipo & $\mathbf{N}$ & Freq. Absoluta & Freq. Relativa \\
\hline MODENS & Qualitativa & 514.886 & 514.886 & $100 \%$ \\
Presencial & & & 354.238 & $69 \%$ \\
A distância & & & 160.648 & $31 \%$ \\
CURGRA & Qualitativa & 513.850 & 513.850 & $100 \%$ \\
Sim & & & 51.222 & $10 \%$ \\
Não & & & 462.628 & $90 \%$ \\
\hline Variáveis do Aluno & Tipo & $\mathbf{N}$ & Média/Freq. Absoluta & DP/Freq. Relativa \\
\hline TURALU & Qualitativa & 514.886 & 514.886 & $100 \%$ \\
A distância & & & 160.648 & $31 \%$ \\
Matutino & & & 22.646 & $5 \%$ \\
Vespertino & & & 5.539 & $1 \%$
\end{tabular}




\begin{tabular}{|c|c|c|c|c|}
\hline Noturno & & & 319.685 & $62 \%$ \\
\hline Integral & & & 6.368 & $1 \%$ \\
\hline ETNALU & Qualitativa & 514.886 & 514.886 & $100 \%$ \\
\hline Branco & & & 174.488 & $34 \%$ \\
\hline Não branco & & & 164.875 & $32 \%$ \\
\hline Não declarado & & & 163.908 & $32 \%$ \\
\hline $\begin{array}{c}\text { Sem } \\
\text { informação }\end{array}$ & & & 11.615 & $2 \%$ \\
\hline$S E X A L U$ & Qualitativa & 514.886 & 514.886 & $100 \%$ \\
\hline Feminino & & & 292.562 & $57 \%$ \\
\hline Masculino & & & 222.324 & $43 \%$ \\
\hline$I D A A L U$ & Quantitativa & 514.886 & 27,7 & 7,69 \\
\hline FINEST & Qualitativa & 464.918 & 464.918 & $100 \%$ \\
\hline Sim & & & 161.444 & $35 \%$ \\
\hline Não & & & 303.474 & $65 \%$ \\
\hline APOSOC & Qualitativa & 514.886 & 514.886 & $100 \%$ \\
\hline Sim & & & 74.107 & $14 \%$ \\
\hline Não & & & 440.779 & $86 \%$ \\
\hline ENSMED & Qualitativa & 514.886 & 514.886 & $100 \%$ \\
\hline Pública & & & 388.163 & $75 \%$ \\
\hline Privada & & & 111.479 & $22 \%$ \\
\hline $\begin{array}{c}\text { Sem } \\
\text { informação }\end{array}$ & & & 15.244 & $3 \%$ \\
\hline TCHINT & Quantitativa & 514.886 & 0,43 & 0,35 \\
\hline
\end{tabular}

Fonte: Dados da pesquisa.

Para evitar problemas com a interpretação dos resultados, optou-se por excluir aquelas observações que não continham informação ou eram imprecisas. As variáveis ETNALU e ENSMED, por exemplo, apresentam categorias "sem informação" e/ou "não declarado". Dessa forma, o total de observações caiu de 514.886 para 291.418. Isso representa uma diminuição de, aproximadamente, $43 \%$ do total de dados iniciais. Apesar disso, enfatiza-se que a quantidade de observações ainda é expressiva para se extraírem conclusões robustas acerca dos impactos dos fatores da IES, do curso e dos alunos na taxa de evasão.

Após esse tratamento, analisou-se a relação entre a evasão (variável dependente) e os fatores da IES, do curso e dos alunos (variáveis independentes) por meio de regressão linear múltipla em cross-section. Entretanto, ao se testar a normalidade dos resíduos, os testes de Shapiro-Francia e Shapiro-Wilk $(\mathrm{p}<0,05)$ indicaram que o modelo de regressão não atendia a esse pressuposto. Assim, recorreu-se à regressão logística binomial. Para tanto, a variável dependente foi dividida, a partir da mediana, em duas categorias: (a) IES com altas taxas de evasão (mediana ao valor máximo); e (b) IES com baixas taxas de evasão (mediana ao valor mínimo). A Equação (2) representa o modelo logístico:

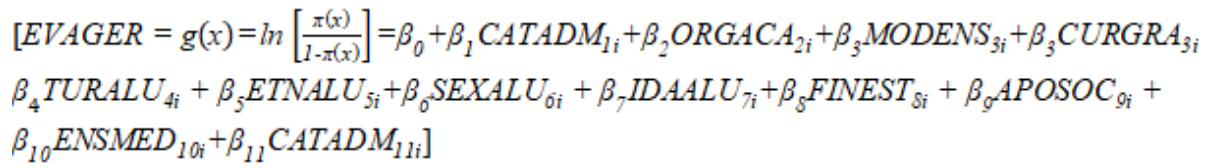


Ressalta-se que as variáveis qualitativas foram transformadas em dummies, conforme orienta Fávero (2015). Além disso, devido à multicolinearidade, a variável CURGRA e as categorias "A distância" e "Integral" da variável TURALU foram omitidas. Os dados forram analisados por meio do Stata v.13. Os resultados retratados na Tabela 3.

Tabela 3 Resultados da regressão logística binomial

\begin{tabular}{lcccc}
\hline EVAGER & Coeficiente & EP & $\mathbf{z}$ & $\mathbf{p}$ \\
\hline CATADM - Privada & 1,9386 & 0,1735 & 11,17 & 0,000 \\
CATADM - Especial & $-0,006$ & 0,1831 & $-0,03$ & 0,974 \\
ORGACA & 0,7523 & 0,0096 & 78,49 & 0,000 \\
MODENS & 2,5418 & 0,0994 & 25,56 & 0,000 \\
TURALU - Matutino & 0,9477 & 0,1007 & 9,41 & 0,000 \\
TURALU - Vespertino & 1,1386 & 0,1134 & 10,04 & 0,000 \\
TURALU - Noturno & 0,5285 & 0,0987 & 5,35 & 0,000 \\
ETNALU & $-0,2567$ & 0,0087 & $-29,50$ & 0,000 \\
SEXALU & $-0,0439$ & 0,0088 & $-5,01$ & 0,000 \\
IDAALU & 0,0248 & 0,0006 & 38,77 & 0,000 \\
FINEST & $-0,0602$ & 0,0091 & $-6,60$ & 0,000 \\
APOSOC & 1,1244 & 0,0227 & 49,63 & 0,000 \\
ENSMED & 0,0538 & 0,0105 & 5,11 & 0,000 \\
TCHINT & $-0,7491$ & 0,0139 & $-54,07$ & 0,000 \\
CONSTANTE & $-3,2254$ & 0,2007 & $-16,07$ & 0,000 \\
\hline N & 291.418 & LR CHI2(14) & & 82.547 \\
PSEUDO R2 & & PROB CHI2 & & 0,000 \\
LOG LIKELIHOOD & -158.882 & & & \\
\hline
\end{tabular}

Fonte: Dados da pesquisa.

Os resultados apontam que as variáveis da IES têm impacto relevante nas taxas de evasão. O coeficiente positivo e significante $(1,9386)$ da CATADM - Privada mostra que as IES da iniciativa privada têm maior propensão a ter mais altas taxas de evasão do que baixas. Isso sugere que, no âmbito privado, há mais evasão de alunos do curso de Ciências Contábeis comparativamente ao âmbito público. Tal resultado é condizente com o estudo de Silva et al. (2007), o qual sustenta que, devido às IES privadas deterem a maioria dos alunos do ensino superior, maior é o peso na média, elevando a taxa de evasão.

Por outro lado, não houve diferença estatisticamente significante entre a taxa de evasão das IES públicas e especiais $(\mathrm{p}=0,974)$, o que indica que a evasão nas IES, cuja categoria administrativa seja especial, é similar à evasão das IES públicas. Adicionalmente, as IES com organização acadêmica considerada não-universitária (faculdade, centro universitários etc.) têm maior probabilidade de ter altas taxas de evasão em relação às IES com organização acadêmica universitária (coef. $=0,7523 ; \mathrm{p}<0,00)$. Essa relação também foi identificada no estudo de Silva et al. (2007), os quais encontraram que as faculdades 
representaram o segmento com maior taxa de evasão $(29 \%)$ se comparadas com as universidades (19\%) e centros universitários (19\%).

Uma possível explicação para esse achado é a de que as universidades são mais eficientes em reter os estudantes, sendo importante interpretar conjuntamente os resultados. Ao avaliar as variáveis CATADM e ORGACA, nota-se que as universidades públicas representam o tipo de IES que têm menor probabilidade de apresentar altas taxas de evasão. Além do ponto de vista da eficiência, é possível que os alunos estejam mais interessados na conclusão do curso de graduação nas universidades públicas do que se estivessem em particulares, uma vez que se presume que o processo de ingresso é mais concorrido e árduo do que nas IES privadas, gerando maior motivação (SILVA FILHO et al., 2007).

Outra possível explicação envolve a reputação das universidades públicas, a qual, geralmente, é mais elevada do que a das IES particulares, além de suas implicações para o mercado de trabalho. É possível entender que a obtenção de uma graduação em uma universidade pública fornece ao futuro trabalhador, de forma geral, maior probabilidade de conseguir emprego (BUENO, 1993). Portanto, os alunos de universidades públicas tenderiam a empregar mais esforços para concluir a graduação, reduzindo, assim, as taxas de evasão.

No que tange às variáveis do curso, percebe-se que essas são relevantes para determinar o nível das taxas de evasão. Especificamente em relação à modalidade de ensino, o coeficiente positivo e significante $(2,5418)$ indica que o EaD tem maior probabilidade de obter elevadas taxas de evasão em comparação com o ensino presencial. Segundo a SEMESP (2016), a evasão no ensino a distância foi de $32 \%$ e, nos cursos presenciais, de $25,4 \%$. A evasão no EaD é uma realidade no Brasil e no mundo e tem, progressivamente, chamado a atenção dos gestores educacionais, uma vez que representa maiores custos para as IES, especialmente, em se tratando de gastos fixos. Uma possível explicação para esse achado é o de que o ensino presencial traz mais motivação ou, ao menos, encoraja mais o aluno a realizar o curso de graduação, enquanto que, no $\mathrm{EaD}$, o estudante precisa ser mais disciplinado para evitar a não conclusão do curso.

O turno em que o aluno faz o curso de graduação também é relevante para explicar o nível de evasão. Nesse sentido, percebe-se maior evasão nas IES em que são oferecidos cursos de Ciências Contábeis no turno vespertino $(1,1386)$ em relação ao ensino integral (categoria omitida). Esse dado importa porque os gestores acadêmicos podem tomar decisões de oferecer cursos de Ciências Contábeis apenas nos períodos em que a evasão é menor, aumentando a eficiência do serviço de educação. Esse resultado é similar aos estudos de Silva 
et al. (2017) e Dias, Theóphilo e Lopes (2010), os quais encontraram maiores taxas de evasão para o período noturno. Por outro lado, Vieira e Miranda (2015) acharam maior evasão no turno integral.

Similarmente às variáveis da IES e do curso, as variáveis dos alunos são relevantes para se estabelecerem os níveis de evasão. Com relação à etnia (ETNALU), nota-se que alunos que se consideram brancos evadem menos do que os que reportam serem não-brancos. O coeficiente negativo e significante (-02567) sugere que a etnia do estudante pode ser um fator que interfere na conclusão do curso, especialmente, quando é associada à renda e à oportunidade de acesso à educação básica de qualidade. Para explorar com maior profundidade esse resultado, elaborou-se a tabela cruzada (não reportada) da variável ETNALU com ENSMED e encontrou-se que 24,73\% (42.186) dos alunos brancos estudaram o ensino médio em escolas particulares, enquanto que esse percentual é de $21,42 \%$ (34.537) para os não-brancos. Isso é um indicativo de que a proporção de alunos brancos que tiveram maior acesso ao ensino básico de qualidade é maior do que a proporção de alunos nãobrancos. Considerando que a formação básica pode afetar a persistência do aluno no ensino superior (DIOGO et al., 2016), é razoável presumir que uma educação de base deficitária levará o aluno a se evadir.

O sexo dos alunos (SEXALU) também é importante para determinar a taxa de evasão das IES. O coeficiente negativo e significante $(-0,0439)$ sinaliza que estudantes do sexo feminino reduzem a probabilidade de a IES obter altas taxas de evasão. Isso é argumentável do ponto de vista de que o sexo dos indivíduos condiciona comportamentos. Homens e mulheres, por possuírem distintos níveis de motivação e persistência, podem tomar decisões diferentes (NAGAI, 2015). Isso pode ocorrer com decisões voltadas à evasão acadêmica. Os achados de Dias, Theóphilo e Lopes (2010), Krüger Júnior et al. (2011), Furtado e Alves (2012), Vasconcelos, Silva e Miranda (2013) e Vieira e Miranda (2015) constataram maiores taxas de evasão associadas aos alunos do gênero masculino.

O coeficiente positivo e significante da variável IDAALU aponta que alunos de maior idade aumentam a probabilidade de a IES obter maior índice de evasão, havendo múltiplas explicações para esse resultado. Primeiramente, alunos mais velhos não têm a mesma motivação de alunos mais jovens devido aos vários compromissos pessoais e/ou profissionais já assumidos. Furtado e Alves (2012) identificaram que os alunos casados ou divorciados têm maior probabilidade de se evadirem, visto que os compromissos externos podem ter prioridade. Em segundo lugar, alunos mais velhos podem não ter tido uma formação básica de 
qualidade, faltando-lhes conhecimentos essenciais para conseguir concluir o ensino superior (MEC, 1996). Em terceiro lugar, os alunos mais velhos podem estar cursando a segunda graduação, o que nem sempre irá complementar a renda ou satisfazer metas profissionais, influenciando, assim, nos seus compromissos com a graduação e com a instituição (BUENO, 1993; TINTO, 1975; DIOGO et al., 2016). Em quarto lugar, é comum que o perfil de estudantes no $\mathrm{EaD}$ seja de indivíduos mais experientes e que já se encontram inseridos no mercado de trabalho e, por isso, podem enfrentam dificuldades de conciliar os estudos com o trabalho e os compromissos externos (DIAS; THEÓPHILO; LOPES, 2010; KRÜGER JÚNIOR et al., 2011; FURTADO; ALVES, 2012; VASCONCELOS; SILVA; MIRANDA, 2013; NAGAI, 2015).

Nota-se ainda, pelo coeficiente significante e negativo $(-0,0602)$, que o financiamento estudantil colabora para diminuir a evasão universitária. Alunos que não possuem financiamento para custear o curso de graduação estão mais propensos a se evadirem (SILVA FILHO et al., 2007; FURTADO; ALVES, 2012; DIOGO et al., 2016). Segundo o relatório da SEMESP (2016), em 2014, as IES privadas que contavam com o financiamento do FIES apresentaram, no primeiro ano de curso, um índice de evasão relativamente baixo $(7,4 \%)$ se comparado com as que não contavam com esse tipo de financiamento $(25,9 \%)$. Dessa forma, a política de financiamento do ensino superior, especialmente no tocante às atribuições do governo, é relevante para estabelecer a eficiência das IES.

A variável APOSOC se mostrou positivamente correlacionada com o nível de evasão $(1,1244)$, sugerindo que alunos que têm apoio social da IES tendem a se evadirem mais, tendo sido esperado dessa variável uma relação inversa (KRÜGER JÚNIOR et al., 2011; DIAS; THEÓPHILO; LOPES, 2010; FURTADO; ALVES, 2012; DIOGO et al., 2016). Uma possível explicação é que alunos que procuram por apoio social naturalmente já estão em estado de necessidade e, portanto, estão mais propensos a se evadirem. Esse é outro ponto que merece maiores investigações.

Por sua vez, a variável ENSMED apresentou coeficiente positivo e significante $(0,0538)$, indicando que alunos que cursaram o ensino médio em escolas públicas tendem a se evadirem mais no ensino superior do que alunos que o cursaram em escolas privadas. Isso ocorre porque há a suposição de que o ensino fundamental e médio de escolas particulares é de melhor qualidade do que o de escolas públicas. Dessa forma, os estudantes provenientes de escolas privadas que se matriculam no ensino superior terão mais facilidade para concluir o 
curso de graduação se comparados aos alunos provenientes de escolas públicas, visto que os primeiros tiveram formação básica mais robusta (MEC, 1996; DIOGO et al., 2016).

Finalmente, a variável TCHINT obteve coeficiente negativo e significante $(-0,7491)$. Esse achado sustenta que alunos que integralizaram mais horas do curso de graduação tendem a se evadirem menos do que estudantes com altas taxas de carga horária a serem integralizadas (FURTADOO; ALVES, 2012). Esse resultado é esperado, tendo em vista que é razoável presumir que estudantes dos últimos períodos têm menor probabilidade de desistir do curso do que os que estão no seu início. Segundo Vieira e Miranda (2015), a evasão nos primeiros períodos está relacionada à inadaptação à vida universitária e/ou à área profissional.

\section{CONCLUSÃO}

O estudo objetivou analisar os fatores que estão relacionados com a evasão nos cursos de Ciências Contábeis. Para tanto, foram coletados dados do Censo Nacional da Educação Superior, os quais viabilizaram os cálculos das taxas de evasão das IES por meio da metodologia de Silva Filho et al. (2007). Além disso, foram coletadas as variáveis independentes relacionadas à IES, ao Curso e aos Alunos.

De forma geral, todas as variáveis consideradas neste estudo se mostraram estatisticamente relevantes para determinar o nível de evasão das IES referente aos cursos de Ciências Contábeis. Destaca-se que a evasão nas IES privadas não-universitárias é superior à de IES públicas e especiais com categoria administrativa universitária.

Os cursos na modalidade $\mathrm{EaD}$ apresentaram maiores probabilidade de altas taxas quando comparados aos cursos presenciais. São questões relacionadas a reputação do ensino superior público e privado e aos tipos de perfil dos estudantes quanto aos seus objetivos e compromissos. O aluno com o objetivo de conseguir o diploma apresenta motivação e habilidade acadêmica que podem refletir diretamente em sua experiência universitária e evasão.

O estudante, ao iniciar a vida universitária, carrega consigo as características anteriores ao ingresso e essas passam a refletir na sua integração ao novo ambiente. Verificouse que as variáveis relacionadas ao período pré-universitário (contexto familiar, atributos individuais e escolaridade anterior) têm forte influência na evasão.

Para as causas externas à instituição, deve-se promover ações para sanar as dificuldades financeiras como oferta de financiamento estudantil e descontos (IES privadas) e bolsas e apoios sociais (IES públicas). Torna-se relevante a orientação vocacional, que poderá 
ser realizada no Ensino Médio por meio de palestras informativas, conversas com profissionais, dentre outras ações, as quais poderão ser empreendidas por instituições de ensino que oferecem os cursos superiores, o que poderia ocorrer em parceria com as escolas de ensino médio.

Assim, os resultados identificados neste estudo podem contribuir com os gestores acadêmicos (diretores e coordenadores de curso) na reformulação do projeto pedagógico e currículo do curso, bem como no oferecimento de atividades de apoio pedagógico a estudantes com baixo desempenho, além de ações pedagógicas propostas para as disciplinas com altas taxas de reprovação e outras atividades no âmbito da educação contábil a fim de minimizar a evasão. Enfatiza-se, da mesma forma, a importância do papel governamental na oferta e estruturação de políticas de financiamento estudantil para redução da evasão, sobretudo, no ensino superior e na oferta de ensino básico de qualidade.

Levantam-se três principais limitações para a pesquisa: (i) Não foi possível avaliar o efeito das variáveis docentes sobre a evasão em decorrência da restrição nos bancos de dados; (ii) Havia variáveis com informações imprecisas, como "não declarado" ou "sem informação"; e (iii) Não foi possível analisar os dados por meio da regressão linear múltipla. Apesar disso, as tentativas de redução de problemas oriundos dessas limitações estão refletidas nas escolhas metodológicas que os autores fizeram e que estão descritas ao longo do trabalho.

Por fim, além das sugestões já expostas, propõe-se que futuros estudos incluam os fatores docentes, os quais poderiam afetar as taxas de evasão das IES, e que se consiga aumentar o período de análise (estudo longitudinal). Em adição, seria enriquecedor para a literatura a análise dos fatores determinantes da evasão à luz de outros enfoques teóricos.

\section{REFERÊNCIAS}

ADACHI, A. A. C. T. Evasão e evadidos nos cursos de graduação da Universidade Federal de Minas Gerais. Belo Horizonte, 2009. 214 f. Dissertação - Mestrado em Educação, UFMG/FaE. Brasil/MEC/SESU.

MINISTÉRIO DA EDUCAÇÃO - MEC. Comissão especial de estudos sobre a evasão nas universidades públicas brasileiras. 1996. Brasília: ANDIFES/ABRUEM/SESU/MEC. Disponível em: < http://www.andifes.org.br/wpcontent/files_flutter/Diplomacao_Retencao_Evasao_Grauacao_e m_IES_Publicas-1996.pdf $>$. Acesso em: 03 jun 2018. 
BUENO, J. L. O. A Evasão de alunos. Paidéia, FFCLRP - USP. Ribeirão Preto, n. 5 p.9-16, ago. 1993. Disponível em: <http://www.scielo.br/scielo.php?script=sci_arttext\&pid=S0103863X1993000200002>. Acesso em: 08 jul. 2018.

CUNHA, J. V. A.; NASCIMENTO, E. M.; DURSO, S. O. Razões e influências para a evasão universitária: um estudo com estudantes ingressantes nos cursos de Ciências Contábeis de instituições públicas federais da região sudeste. In: Congresso USP de Controladoria e Contabilidade, 14, São Paulo. Anais Eletrônicos... São Paulo: USP, 2014. Disponível em: $<$ http://www.congressousp.fipecafi.org/web/artigos142014/403.pdf. $>$. Acesso em: 08 jul. 2018.

DIAS, E. C. M.; THEÓPHILO, C. R.; LOPES, M. A. S. Evasão no Ensino Superior: estudo dos fatores causadores da evasão no curso de ciências contábeis da universidade estadual de montes claros - Unimontes - MG. In: Congresso USP de Controladoria e Contabilidade, 10, São Paulo. Anais Eletrônicos... São Paulo: USP, 2010. Disponível em: < http://www.congressousp.fipecafi.org/anais/artigos102010/419.pdf $>$. Acesso em: 08 jul. 2018.

DIOGO, M. F. et. al. Percepções de coordenadores de curso superior sobre evasão, reprovações e estratégias preventivas. Avaliação: Revista da Avaliação da Educação Superior (Campinas), Sorocaba, v. 21, n. 1, p. 125-151, Mar. 2016. Disponível em: < http://www.scielo.br/scielo.php?script=sci_arttext\&pid=S1414-

$40772016000100125 \& \operatorname{lng}=$ en\&nrm=iso $>$. Acesso em: 08 jul. 2018.

FÁVERO, L. P. Análise de Dados: Modelos de Regressão com Excel, Stata e SPSS. 2016. Rio de Janeiro: Elsevier, 2015.

FURTADO, V. V. A.; ALVES, T. W. Fatores determinantes da evasão universitária: uma análise com alunos da UNISINOS. Revista Contemporânea de Economia e Gestão, v. 10, n 2, jul/dez 2012. Disponível em:

$<$ http://www.periodicos.ufc.br/contextus/article/view/919/896>. Acesso em: 03 jun 2018.

\section{GILIOLI, R. de S. P. Evasão em Instituições Federais de Ensino Superior no Brasil:} expansão da rede, SISU e desafios. Disponível em: < http://www2.camara.leg.br/documentose-pesquisa/publicacoes/estnottec/areas-da-conle/tema11/2016_7371_evasao-em-instituicoesde-ensino-superior_renato-gilioli>. Acesso em: 03 jun. 2018.

GOIS, A. O custo do abandono. O Globo. 2016. Disponível em:

$<$ http://oglobo.globo.com/sociedade/educacao/o-custo-do-abandono-20588816>. Acesso em: 03 jun 2018.

Instituto Nacional de Estudos e Pesquisas Educacionais Anísio Teixeira (INEP). Censo Nacional da Educação Superior. Disponível em: < http://portal.inep.gov.br/web/guest/microdados>. Acesso em: 03 jun 2018.

KRÜGER-JÚNIOR, P. R.; et al. Pesquisando causas e possíveis soluções para a problemática da evasão em um curso de administração numa universidade pública no sul do Brasil. In Colóquio Internacional sobre Gestão Universitária na América do Sul e II Congresso Internacional IGLU, Florianópolis, SC, Brasil, 2. Anais Eletrônicos... Santa 
Catarina: UFSC, 2011. Disponível em:

$<$ http://repositorio.ufsc.br/xmlui/handle/123456789/31139>. Acesso em: 08 jul. 2018.

LOBO, M. B. de C. M. Panorama da Evasão no Ensino Superior Brasileiro: Aspectos Gerais das Causas e Soluções. ABMES Cadernos, São Paulo, n. 25, p. 09-58, 2012. Disponível em: $<$ http://www.abmes.org.br/abmes/public/arquivos/publicacoes/Cadernos25.pdf $>$. Acesso em: 03 jun 2018.

MOEHLECKE, S. Avaliação Institucional no Ensino Superior: como acompanhar a trajetória dos estudantes de graduação? In: Simpósio Brasileiro de Política e Administração da Educação, junto com o V Congresso Luso-Brasileiro e o Colóquio Ibero-Americano de Política e Administração - ANPAE (Associação Nacional de Política e Administração da Educação), 23, Rio Grande do Sul. Anais Eletrônicos... Rio Grande do Sul: ANPAE, 2007. Disponível em: $<$ http://www.anpae.org.br/congressos_antigos/simposio2007/401.pdf $>$. Acesso em: 08 jul. 2018.

MUNIZAGA, F., CIFUENTES, M., BELTRÁN, A. Retención y abandono estudiantil en la Educación Superior Universitaria en América Latina y el Caribe: Una revisión sistemática. Archivos Analíticos de Políticas Educativas, [S.I], v. 26, n. 61, maio 2018. Disponível em: $<$ https://epaa.asu.edu/ojs/article/view/3348>. Acesso em: 07 jul. 2018.

NAGAI, N. P. A Evasão Universitária: Uma Análise Além dos Números. In: Congresso de Administração do Sul do Mato Grosso, 3, Mato Grosso. Anais Eletrônicos... Mato Grosso: UFMT, 2015. Disponível em:

$<$ http://eventosacademicos.ufmt.br/index.php/CONASUM/2015/paper/viewFile/5/3>. Acesso em: 18 jan 2018.

SANTOS, P. V. S. Adaptação à Universidade dos Estudantes Cotistas e Não Cotistas: Relação entre Vivência Acadêmica e Intenção de Evasão. Salvador, 2013. 109 f. Dissertação - (Mestrado em Psicologia) - Universidade Federal da Bahia/POSPSI, 2013.

Sindicato das Mantedoras de Ensino Superior (SEMESP). Mapa do Ensino Superior no Brasil 2016. Disponível em:

$<\mathrm{http}: / /$ convergenciacom.net/pdf/mapa_ensino_superior_2016.pdf $>$. Acesso em: 12 maio 2018.

SILVA FILHO, R. L. L.; MOTEJUNAS, P. R.; HIPÓLITO, O.; LOBO, M. B. de C. M. A evasão no ensino superior brasileiro. Cadernos de Pesquisa, São Paulo, v. 37, n. 132, p. 641 659, set./dez. 2007. Disponível em: < http://www.scielo.br/pdf/cp/v37n132/a0737132>. Acesso em: 08 jul. 2018.

SILVA FILHO, R. L. L.; LOBO, M. B. de C. M. Esclarecimentos Metodológicos sobre os Cálculos de Evasão. 2012. Disponível em:

$<$ http://www.institutolobo.org.br/imagens/pdf/artigos/art_078.pdf >. Acesso em: 03 jun 2018.

SILVA, I. J. A. da; et al. Estratégias das Coordenações dos Cursos de Ciências Contábeis para Combater a Evasão. In: Congresso USP de Iniciação Científica em Contabilidade, XIV, São Paulo, Anais Eletrônicos... São Paulo: USP, 2017. Disponível em: < 
http://www.congressousp.fipecafi.org/anais/AnaisCongresso2017/ArtigosDownload/190.pdf $>$ Acesso em: 10 jul. 2018.

SPADY, W. G. Dropouts from higher education: An interdisciplinary review and synthesis. Interchange, v. 1, n. 1, 64-85, 1970. Disponível em:

$<$ https://link.springer.com/article/10.1007/BF02214313>

SPADY, W. G. Dropouts from higher education: Toward an empirical model. Interchange, v. 2, n. 3, 38-62, 1971. Disponível em: <https://link.springer.com/article/10.1007/BF02282469>

VASCONCELOS, A. L. F. de S.; SILVA, M. N. da; MIRANDA, N. P. de. Um estudo sobre as causas da evasão no ensino superior no curso de Ciências Contábeis e Atuariais. Revista Brasileira de Contabilidade, [S.1.], n. 195, p. 20-31, jan. 2013. Disponível em: $<$ http://rbc.cfc.org.br/index.php/rbc/article/view/991>. Acesso em: 08 jul. 2018.

VIEIRA, D. B.; MIRANDA, G. J. O Perfil da Evasão no Curso de Ciências Contábeis da Universidade Federal de Uberlândia: Ingressantes entre 1994 A 2013. In: Congresso de Contabilidade, 9, Santa Catarina. Anais Eletrônicos... Santa Catarina: UFSC, 2015. Disponível em: < http://dvl.ccn.ufsc.br/congresso_internacional/anais/6CCF/43_16.pdf $>$. Acesso em: 18 jan. 2018.

TINTO, V. Dropout from higher education: a theoretical synthesis of recent research. Review of educational Research, v. 45, n. 1, p. 89-125, 1975. Disponível em: < https://journals.sagepub.com/doi/10.3102/00346543045001089> 